\title{
Emergência, Cuidado e Assistência à Saúde de Crianças com Síndrome Congênita do Zika Vírus: notas sobre os serviços de saúde e a atuação das mães em Pernambuco
}

\author{
Marion Teodósio de Quadros ${ }^{a}$ \\ Silvana Sobreira de Matos ${ }^{\mathrm{b}}$ \\ Ana Cláudia Rodrigues da Silva ${ }^{c}$
}

O nascimento de criancas com Síndrome Congênita do Zika vírus (SCZ), especialmente na região Nordeste, fez com que Pernambuco, o Brasil e a OMS decretassem emergência em saúde pública. Este artigo aborda sobre algumas das continuidades e descontinuidades percebidas em relação à assistência durante o estado de emergência em saúde pública e após a sua finalizacão, apreciando como a Secretaria Estadual de Saúde (SES) respondeu ao fim da epidemia e o peso social da doença para as mães, no processo de descoberta e tratamento da SCZ das crianças, comparando depoimentos e observações de profissionais e mães de crianças com SCZ, em Pernambuco, epicentro da epidemia. Integra a pesquisa antropológica 'Etnografando cuidados', iniciada em 2016. O primeiro e segundo itens refletem sobre as ações institucionais, principalmente da SES. O terceiro item enfatiza como as mães das crianças com SCZ percebem o que lhes chega pelos serviços públicos de assistência.

Zika vírus, Saúde pública, Cuidado, Gênero, Maternidade.

No segundo ${ }^{1}$ semestre de 2015, os serviços de saúde de Recife notificaram um aumento exponencial do número de casos de micro-

\footnotetext{
a Professora Associada do Programa de Pós-Graduação em Antropologia, Departamento de Antropologia e Museologia (UFPE). Email: marionteodosio@yahoo.com.

b Pesquisadora bolsista de Pós-Doutorado na Pós-Graduação em Antropologia, Departamento de Antropologia e Museologia (UFPE). Email:silvanasmatos@gmail.com.

c Professora Adjunta do Programa de Pós-Graduação em Antropologia, Departamento de Antropologia e Museologia (UFPE). Email:acrodriguess@gmail.com.
} 
cefalia em bebês recém-nascidos. A neuropediatra Vanessa Van der Linden, médica de um hospital público, constatou que os exames de rotina para identificar a causa da microcefalia, eram negativos, resultando na atribuição de uma causa desconhecida. Dos 2.975 casos suspeitos no Brasil, cerca de $40 \%$ ocorreram em Pernambuco (Brasil 2016), epicentro da epidemia.

Em novembro de 2015, após ter sido estabelecida a associação entre o surto de microcefalia e a infecção pelo vírus Zika da mãe durante a gravidez, o Governo de Pernambuco decretou situação de emergência; no fim do mês, o Ministério da Saúde do Brasil declarou a Emergência em Saúde Pública de Importância Nacional (ESPIN). Com o aumento dos casos de microcefalia e a possível associação entre a infecção pelo Zika vírus e as síndromes neurológicas ou malformações congênitas, em 10 de fevereiro de 2016, a Organização Mundial da Saúde (OMS) declarou a Emergência de Saúde Pública de Importância Internacional (ESPII) (Silva, Matos \& Quadros 2017).

A organização das ações relacionadas à epidemia causada pelo mosquito Aedes Aegypti contou com uma ênfase em vigilância e atenção em saúde, necessária ao seu controle, reunindo serviços de saúde, instituições de assistência e pesquisa, congregando profissionais e cientistas das áreas de pediatria, saúde reprodutiva, neurologia, doenças infecciosas, biologia e epidemiologia, em sua maior parte.

Nos primeiros meses de 2017, houve uma redução de $95 \%$ das notificações de casos de infecção pelo Zika vírus e diminuição das notificações de SCZ, levando o Governo Brasileiro a decretar o fim do Estado de Emergência em 11/05/2017 (Brasil 2017c). Isso não significou o fim do combate ao mosquito nem ao tratamento das crianças, mas o fim da epidemia. Até o fim de 2019, havia 470 casos confirmados de SCZ em Pernambuco (Pernambuco 2019) e 3.332 casos confirmados em todo o Brasil (Brasil 2019a).

Comparado ao surto de Ebola na África Ocidental, cuja demora na atribuição da emergência contribuiu para que a resposta à epidemia não fosse tão boa quanto se esperava (Wilkinson; Leach 2014 e 
2015), houve pronta resposta do Estado ao surto (Brasil 2017b), mas os esforços das mães e cuidadoras de bebês com SCZ e as ações de prevenção, controle e cuidado dos governantes vem refletindo algumas desigualdades sociais tanto na prevalência da zika e da microcefalia quanto no peso que significa arcar com as consequências do surto (Silva, Matos \& Quadros 2017; Scott et al 2017; Scott et al 2018; Lira, Scott \& Meira 2017).

O nascimento de crianças com SCZ decorrentes da epidemia do Zika ressaltam desigualdades de gênero, classe, raça e região, especialmente no trabalho de cuidado (Hirata 2016). Há prevalência de mulheres nordestinas, pretas ou pardas e pobres, grande parte com renda inferior a 1 salário mínimo (Pernambuco 2019), moradoras das periferias dos grandes centros urbanos como as principais ou únicas responsáveis pelos cuidados com essas crianças, ou seja, são essas mães que estão arcando com as consequências práticas da SCZ de suas crianças, o que coloca a questão de divisão de trabalhos de cuidado como pauta para o debate (Scavone 2001 e 2004; Guimarães et al 2011; Ayres 2009; Tronto 1997; Hirata 2016; Silva, Matos \& Quadros 2017; Scott et al 2017; Scott et al 2018), uma vez que sob elas recai o maior peso social da doença (Brooks 2016; Diniz 2007 e 2016; Hirata 2016; Sullivan 2016; Unnithan et al 2016).

Considerando que o Brasil se caracteriza por política sanitária de 'universalismo progressivo' e longo histórico de participação e cidadania na relação com o Estado (Shankland \& Cornwall 2007), desde o surgimento do surto de infecção por Zika vírus e do nascimento de crianças com SCZ, a partir de 2015, Estado e cidadania configuraram uma relação que ora realçava a efetividade dos esforços para uma resposta satisfatória às populações mais vulneráveis, ora indicava que as políticas governamentais tentam passar as responsabilidades para as cidadãs, como destacamos em outra ocasião (Silva, Matos \& Quadros 2017; Matos, Quadros \& Silva 2019).

No contexto da SCZ, o cuidado passa a ser um conceito fundamental nessa relação entre Estado e cidadania. Ele refere o apoio es- 
tatal nas atividades profissionais de cuidado, e também práticas e processos que incluem não somente as profissões, mas a família, o parentesco, as relações de gênero, emoções e sentimentos presentes em relações variadas de acompanhamento, ajuda, afeto e atenção relacionadas às questões de saúde, trabalho, vida familiar e comunitária etc (Campos, Quadros \& Santos 2010; Lima 2016; Hirata \& Debert 2016).

Este artigo faz parte de uma pesquisa ${ }^{2}$ realizada entre equipes e FAGES (Família, Gênero e Sexualidade) da Universidade Federal de Pernambuco, iniciada em 2016 no estado de Pernambuco/Brasil, cujo objetivo foi conhecer a experiência das mulheres e suas redes familiares afetadas pela Síndrome Congênita do Zika (ZCV), e associá-la a um esforço para ampliar a sensibilidade e a capacidade de resposta do sistema de saúde à epidemia causada pelo vírus Zika. Trata-se de uma pesquisa etnográfica e multi-localizada, com observações e entrevistas com pessoas envolvidas em práticas de cuidado, principalmente mães de crianças, profissionais de saúde e serviços sociais.

Esse trabalho aborda algumas das continuidades e descontinuidades percebidas na atuação da assistência à saúde durante o estado de emergência em saúde pública e após a sua finalização, comparando depoimentos e observações de profissionais e mães de crianças com SCZ. Como campo de observação a escolha de Pernambuco se deu por ser o local com maior número de casos confirmados durante a epidemia e procurou-se destacar as tensões e percepções das práticas de cuidado envolvidas para apreciar como a SES respondeu ao fim da epidemia e evidenciar o peso social da doença recaiu sobre as mães em todo o processo de descoberta e tratamento da SCZ das crianças. A análise empreendida se baseia nos artigos já publicados da pesquisa (Silva, Matos \& Quadros 2017; Matos, Silva \& Quadros 2018; Matos \& Quadros 2018; Matos, Quadros \& Silva 2019; Scott et al 2017; Scott et al 2018; Lira, Scott \& Meira 2017; Quadros, Scott \& Faya 2020)3.

Organizamos o texto em 3 itens. No primeiro, evidenciamos os principais aspectos organizacionais e de atuação dos serviços públicos 
de saúde durante o estado de emergência que levou ao reconhecimento de Pernambuco como um estado que conseguiu organizar uma boa resposta à epidemia. Evidentemente que ações de outras secretarias, especialmente as de assistência social, educação e transporte também foram acionadas neste período e fizeram parte de grupo de gestão cuja sede foi a Secretaria Estadual de Saúde. Entretanto, neste artigo, estaremos priorizando especialmente as ações da Secretaria Estadual de Saúde ${ }^{4}$. No segundo item, comparamos estas ações e estrutura organizacional da Secretaria Estadual de Saúde com as do período posterior à finalização do estado de emergência, tendo como uma das fontes para compreensão das ações desenvolvidas, dados de dois boletins epidemiológicos quanto a número de atendimentos em puericultura, estimulação precoce e atendimento especializado. No terceiro item, procuramos ver como as medidas adotadas em termos de ações e organização foram apreciadas pelas gestantes e mães em termos de realização e resultados de exames, atendimento e modificações de rotina.

Compreendemos que a avaliação de serviços de saúde tem um campo próprio, cujas metodologias e debates formam uma área de discussão específica. Com desenvolvimento inicial nos anos de 1980, a área de avaliação vem crescendo desde os anos de 1990. Criticada pelo uso instrumental em várias áreas e setores relacionados às políticas públicas, podem se tornar meios de opressão e controle, especialmente quando o foco está apenas no aprimoramento dos meios e da gestão com base em resultados, o chamado gerencialismo (Furtado et al 2018:7-9). Como bem apontam Furtado et al:

"Essa modalidade de gestão é considerada como método ideal pela racionalidade do mercado, mas incompatível com a lógica pública, como em parte se demonstrou com a experiência do Programa Nacional de Melhoria do Acesso e da Qualidade da Atenção Básica (PMAQ-AB), do Ministério da Saúde" (Furtado et al 2018:7).

Há um esforço em desenvolver enfoques emergentes e qualitativos na América Latina para consolidar propostas nacionais que extrapolem as amarras entre objetivos e resultados. Dentre tais esforços, pode- 
mos inserir a análise antropológica da saúde (Minayo 2000; Langdon 2010; Langdon, Follér \& Maluf 2012) e a análise antropológica da avaliação (Gussi \& Oliveira 2016; Spiess 2016) que nos convidam a mergulhar na dimensão cotidiana por meio de uma etnografia da experiência empírica das políticas públicas, utilizando a observação, as entrevistas e a proximidade como recursos para compreender ações institucionais e beneficiários, procurando ampliar o alcance dos significados dos resultados e dos impactos de tais políticas (Gussi \& Oliveira 2016; Lira, Scott \& Meira 2017). Desse modo, o primeiro e segundo itens refletem sobre as ações institucionais, dando maior realce a um dos órgãos fundamentais para a organização e coordenação do enfrentamento à epidemia do Zika, que é a Secretaria Estadual de Saúde (SES). O terceiro item procura enfatizar como as mães das crianças com SCZ percebem o que lhes chega pelos serviços públicos de assistência, especialmente os de saúde, a partir das ações municipais e estaduais, levando em conta que as ações planejadas e organizadas pela SES, por meio da qual se concretizaram as políticas de enfrentamento, estão em constante relação com o que foi preconizado pelo Ministério da Saúde brasileiro e a capilarização para as ações municipais.

\section{A organização dos serviços de saúde durante o estado de emergência}

A declaração da emergência internacional possibilitou o aporte de grande quantidade de recursos disponibilizados ao governo brasileiro e de mecanismos facilitadores do acesso aos cuidados, às medidas preventivas e de controle e vigilância, além do desenvolvimento de muitas pesquisas, cujo financiamento contava com colaboração suntuosa da união europeia e de outras instituições estrangeiras ligadas á saúde e à pesquisa, pelo estabelecimento de consórcios internacionais. Pouco se sabia sobre as infecções e síndromes neurológicas dos bebês associadas ao zika vírus das mães, durante a gravidez, o que tornava mais relevante a colaboração entre pesquisa e atendimento, conforme destacamos em outro trabalho (Quadros, Scott \& Faya 2020). 
No nível nacional, a Portaria Interministerial N. 405 de 15/03/2016, publicada no dia 16 de março de 2016, por exemplo, se referia, entre outras coisas, a repasses de 15,2 milhões de reais aos estados e municípios, para apoiar as estruturas de atenção às crianças.

Como evidenciou Dr. Carlos Brito (2017:37), o Ministério da Saúde teve um destacado papel de articulador na investigação, apoio e descoberta da associação. Os organismos de investigação e assistência dos estados federativos tiveram um papel importante na articulação de medidas para detecção e diagnóstico e na posterior adaptação da rede de saúde pública para o atendimento ao estado de emergência.

Durante o processo de diagnóstico da epidemia e de seus efeitos, foi possível observar que a microcefalia estava associada a outros distúrbios neurológicos, auditivos e visuais. Essa ampliação de problemas associados fez com que passasse a ser chamada de 'Síndrome Congênita do Zika vírus' (SCZ) (Brito 2017).

Pernambuco, um dos locais mais atingidos pelo grande número de bebês nascidos com SCZ, foi considerado um estado que conseguiu dar respostas rápidas à epidemia. Além de ter sido o local do primeiro mutirão para investigação do aumento de casos de microcefalia, teve destaque na articulação da rede de atenção e vigilância, lançando, ainda em novembro de 2015, o Primeiro Protocolo Clínico e Epidemiológico estadual, que teve uma versão revisada no mês seguinte (Brito 2017).

Essa iniciativa não seria possível se não houvesse uma convergência de esforços na organização da rede de referência de atenção à saúde, da investigação dos casos e da reabilitação. É nesse contexto que se destacam as ações do estado para a assistência das grávidas acometidas pelo Zika vírus e das crianças com SCZ. Segundo informações contidas no site da Secretaria Estadual de Saúde ${ }^{5}$ e aquelas que analisamos em vários dos trabalhos já publicados mencionados na introdução deste artigo, as ações expressivas desse estado de emergência realizadas foram desenvolvidas em oito áreas: 
1) Uma ênfase muito forte no controle do vetor foi intensificada com o monitoramento de ações de combate ao mosquito e da análise de indicadores epidemiológicos realizados por ações inter setoriais do Comitê Estadual de Combate ao Aedes aegypti e do Centro Integrado de Comando e Controle Regional - CICCR.

2) Busca ativa de casos notificados e a realização de mutirões para encerramento de casos em investigação. Foram oito mutirões, de 01/04/2016 a 27/07/2016, realizados em Recife, Caruaru e Petrolina, incluindo entre locais a AACD (Recife), o Hospital Barão de Lucena (Recife) e o Hospital Mestre Vitalino (Caruaru), resultaram em 656 atendimentos realizados, dos quais 49 estavam contaminados pelo vírus, 593 descartados e 14 continuaram em investigação. Aliás, os casos inconclusivos ou que continuam em investigação são uma realidade até os dias de hoje, colocando em evidência tanto a dificuldade do diagnóstico em alguns casos, quanto a falta de conhecimento das formas de manifestação da doença.

3) As crianças com SCZ tiveram prioridade no atendimento em saúde e assistência social em relação às outras crianças com outras deficiências, por causa da excepcionalidade do caso (Matos, Silva \& Quadros 2018), pelo caráter desconhecido da doença e do prognóstico para as crianças, como indicado na fala de uma gestora:

Então é novidade pras mães, é novidade para os profissionais. A gente está há dois anos desse boom, mas assim, a gente ainda se depara com muita novidade. Então, essas crianças são uma caixinha de surpresas. Um dia elas precisam de uma coisa, outro dia estão precisando de outra. E a gente vai tentando adequar a estrutura, a atenção, da forma que a gente pode para melhorar a vida dessas famílias 6 .

A Central de Regulação do Estado, responsável por organizar o fluxo de atendimento na rede pública de saúde de média e alta complexidade (atendimentos, consultas, internações, procedimentos ambulatoriais), bem como a reabilitação, coloca as crianças com SCZ em fluxo diferenciado de atendimento, de modo que elas esperam menor tempo para acessar os serviços de saúde e assistência social, de acordo com a Portaria Interministerial $n^{\circ} 405$, de 05 de março de 2016, que instituiu a Estratégia de Ação Rápida para o fortalecimento da Atenção à Saúde e da Proteção Social de crianças com microcefalia (Brasil 2019b).

4) A Criação da área técnica para a vigilância da SCZ em âmbito estadual, a partir de março de 2016, que ilustra a institucionalização da 
organização requerida pela situação de emergência dentro da Secretaria Estadual de Saúde de Pernambuco.

5) A implantação do Núcleo de Apoio às famílias de crianças com microcefalia (NAFCM), em maio/junho de 2016, com uma coordenadora e 13 apoiadores para "coordenar, monitorar e apoiar as ações regionalizadas de busca ativa, diagnóstico, reabilitação e acompanhamento das crianças notificadas com a Síndrome Congênita do Zika Vírus e respectivas famílias"?

Nesse sentido, o NAFCM é uma organização que acompanha todas as etapas importantes da relação das crianças com SCZ e suas famílias com os serviços de saúde e assistência. A necessidade de sua criação e implantação deve-se aos problemas relacionados a cada uma dessas etapas, que foram se apresentando durante o processo de descoberta da epidemia do vírus Zika, associação com a SCZ, capacidade variada dos serviços municipais em detectar, notificar e, principalmente, confirmar casos de SCZ, problemas no atendimento especializado e na intervenção precoce.

6) A ampliação da rede de reabilitação também foi uma meta que beneficiou o atendimento, pois diante da 'prioridade da prioridade', a reabilitação se destacou como uma atividade essencial para a intervenção precoce, como maneira de reduzir danos. No início da epidemia existiam apenas dois centros de referência: o IMIP (Instituto de Medicina Integral Professor Fernando Figueira) e a AACD (Associação de Assistência à Criança Deficiente), ambos localizados em Recife. Em junho de 2016 eram 26 unidades em vários municípios, embora a maior parte continuasse concentrada em Recife ${ }^{8}$.

7) Qualificação dos profissionais de saúde de diversas especialidades e serviços com capacitações sobre temas relacionados a atendimentos de urgência e emergência, reabilitação e puericultura, realizadas entre 2016 e 2017, para mais de 2.400 participantes (Pernambuco 20/03/2018) e convocação de mais de 3.300 profissionais de diversas áreas da saúde, incluindo 300 médicos, com uma preocupação muito grande na descentralização e regionalização da assistência (Pernambuco 06/12/2016).

8) investimento de 3 milhões de reais em pesquisas através do edital 04/2016, intitulado 'Estudos e pesquisas para políticas públicas estaduais apoio emergencial para estudo do vírus zika', que incluiu pesquisas sobre microcefalia provocada pelo zika vírus, pela Fundação de Amparo à Pesquisa de Pernambuco (FACEPE). 
Dentre essas áreas, a questão da prioridade da prioridade, para a qual temos chamado atenção (Silva, Matos \& Quadros 2017; Matos, Silva \& Quadros 2018; Matos, Quadros \& Silva 2019), expressa a grande variedade de tensões cotidianas e também globais ao mesmo em tempo que ilustra a grande preocupação com o controle da epidemia e a assistência em estado de emergência.

Como mencionamos em outro artigo (Matos, Quadros \& Silva 2019), no âmbito internacional, a prioridade da prioridade parece responder a situação de excepcionalidade e desconhecimento da doença que acompanhou a emergência, uma vez que nas três primeiras já declaradas pela OMS (Gripe A [H1N1] em 2009, o Poliovírus em 2014 e o Ebola em 2014) havia conhecimento prévio das etiologias, formas de propagação e prevenção (Heymann et al 2016; Garcia 2018; Bueno 2017). Além disso, a epidemia do vírus Zika é a única que teve como consequência o nascimento de bebês com deficiência (Matos $\&$ Quadros 2018).

Também evidenciamos (Matos \& Quadros 2018) que a rapidez com que a emergência foi decretada sofreu influência da gravidade da situação enfrentada e da experiência da OMS em relação à ESPII relacionada ao Ebola, na qual a demora da decretação foi avaliada como um ponto negativo que influenciou uma resposta que não foi considerada excelente.

A prioridade da prioridade, portanto, pode ser compreendida como uma atitude que envolve a necessidade de respostas rápidas, desconhecimento da infecção pelo Zika e da SCZ, bem como dos seus efeitos, em uma situação epidêmica singular que tomou parte da construção do estado de emergência. Algumas questões e atores envolvidos nos níveis estadual e municipal, entretanto, problematizam essa priorização (Silva, Matos \& Quadros 2017).

Dentro da própria SES ou ainda entre as equipes de saúde municipais há quem não concorde com esta priorização, uma vez que as pessoas com deficiência possuem atendimento prioritário garantido pela Lei no. 10.048, no Brasil, desde o ano 2000. Como destacamos 
em outro trabalho (Matos, Silva \& Quadros 2018), alguns gestores e famílias questionam a prioridade em relação a outras deficiências. Uma gestora argumentou que a prioridade deveria ser dada de acordo com a gravidade da deficiência e a necessidade de reabilitação:

Eu não concordo muito com esse fluxo. Para mim tinha que ser um fluxo único. Agora o que teria que ser diferenciado? A prioridade deveria ser pelo grau de necessidade, pela complicação, pela gravidade da criança, não por ser $\mathrm{A}, \mathrm{B}$ ou $\mathrm{C}$. O médico sabe avaliar... tanto é que existe um médico regulador na regulação. [...] Então assim, eu acho que deveria ter uma prioridade, mas não por diagnóstico, mas por necessidade, por tipo de gravidade?

No caso das famílias, há também divergências entre aquelas que têm filhos com SCZ e as que possuem filhos com outras deficiências. Enquanto as famílias afetadas pelo Zika defendem o fluxo diferenciado como uma questão de justiça, uma reparação pela negligência do Estado em controlar o mosquito Aedes aegypti, vetor da doença, as famílias de crianças com outras deficiências se sentem esquecidas mais uma vez (Scott et al 2017; Scott et al 2018; Matos \& Quadros 2018)!

A implantação da rede de atenção à saúde para a epidemia contou com uma forte adequação dos equipamentos de saúde existentes, elaborou protocolos e fluxos assistenciais específicos, com regulação do acesso. Dentro dessas ações, é preciso destacar o monitoramento diário dos casos notificados e a campanha de mobilização social, na qual se enfatizava o 'macro amor', o 'macro respeito' e a 'macro atenção', como maneira de chamar a atenção para a população de crianças com SCZ e da discriminação que vinham sofrendo.

Todas essas ações contaram com a interlocução e a pressão das associações de mães, a UMA (União de Mães de Anjos) e a AMAR (Aliança de Mães e Famílias Raras), que congregaram, no decorrer da epidemia, uma grande quantidade de mães insatisfeitas com a assistência que o Estado estava prestando. Como as próprias mães argumentam, a situação que vivem se deve a omissão do Estado em relação ao saneamento básico e a precariedade do atendimento à saúde (Silva, 
Matos \& Quadros 2017; Matos, Silva \& Quadros 2018; Matos \& Quadros 2018; Matos, Quadros \& Silva 2019; Scott et al 2017; Scott et al 2018; Lira, Scott \& Meira 2017).

Podemos adicionar, ainda, as limitações legais ao aborto, atendimento e insumos de pouca qualidade para a saúde sexual e reprodutiva, a responsabilização da mulher e mãe pelos cuidados com a casa e a família, a precarização maior do trabalho das mulheres, o recebimento de salários menores que os dos homens e o tempo livre menor que os dos homens como indicadores da grande desigualdade de gênero, todos estes aspectos estão fortemente relacionados ao peso social da infecção pelo Zika e ao nascimento de crianças com SCZ (Brooks 2016; Diniz 2007 e 2016; Hirata 2016; Sullivan 2016), uma vez que estavam presentes na vida das mulheres antes da epidemia e agora assumem novos significados na luta para o atendimento de seus filhos com SCZ, requerendo mais tempo, mais sacrifícios, abdicação de projetos individuais e familiares, aumento do tempo de cuidado e diminuição do tempo livre (Lira, Scott \& Meira 2018; Scott et al 2017; Scott et al 2018).

De acordo com os dados do Boletim Epidemiológico (Brasil 2017a), no período de 8/11/2015 a 14/01/2017 foram confirmados 392 (aproximadamente 18\%) casos de crianças com SCZ, de um total de 2.163 casos identificados. Como o atendimento prioritário diz respeito somente aos casos confirmados, cerca de 72\% (292) dos bebês foram atendidos pela puericultura, aproximadamente 45\% (177) pela estimulação precoce e 99,7\% (391) pelo atendimento especializado.

Quando comparamos essa cobertura com a dos outros estados da federação, Pernambuco se destaca como o Estado com maior número de atendimentos realizados, exceto na estimulação precoce, onde ocupa a terceira posição. A cobertura, do ponto de vista dos realizadores das ações em saúde e vigilância, foi destacada como pioneira e abrangente (Brasil 2017b; Brito 2017).

Entretanto, essa cobertura e o reconhecimento pela atuação não se deram sem a pressão das mães e a nova configuração que as de- 
sigualdades sociais e econômicas, acrescidas das necessidades e requisitos para o atendimento nos serviços de saúde e assistência, provocaram na vida dessas mulheres, trazendo novas responsabilidades relacionadas à confirmação da SCZ em suas crianças e as obrigações decorrentes dos compromissos assumidos para o diagnóstico e o tratamento da SCZ. A apreciação que elas fazem quanto ao oferecimento dos serviços de saúde e assistência social, bem como a qualidade do atendimento prestado é bem diferente da avalição feita pelos próprios serviços, como veremos no item 3.

\section{A atuação após a emergência}

Nos primeiros meses de 2017, houve uma redução de 95\% das notificações de casos de infecção pelo Zika vírus e de sua associação com a SCZ, levando o Governo Brasileiro a decretar o fim do Estado de Emergência Nacional e a desativação do Centro de Operações de Emergências em Saúde Pública (COES), em 10 de julho de 2017 (Brasil 2017c), por meio da Portaria N. ${ }^{\circ} 1682$.

Isso não significou o fim do combate ao mosquito nem ao tratamento das crianças, mas o fim da epidemia. Os desafios enfrentados no período de emergência não foram superados, ainda há desconhecimento da história da infecção pelo vírus Zika e da SCZ. A necessidade de conhecer melhor suas formas de manifestação e desenvolvimento reforça a importância contínua de novas pesquisas que ofereçam novas evidências científicas. As lacunas no conhecimento da doença e de suas consequências para as crianças com SCZ também colocam novos desafios para a assistência, levando a uma preocupação constante com a adequação e organização da rede assistencial, além da parceria com a vigilância. Isso tudo fez o MS definir que:

“apesar da desativação do COES, as ações e as estruturas mobilizadas pela ESPIN seriam mantidas por período indefinido, considerando que ainda existem lacunas importantes a respeito da história natural da infecção pelo vírus Zika e suas consequências no crescimento e no desenvolvimento das crianças" (Brasil 2017e:2). 
No Estado de Pernambuco, não ouvimos falar mais de mutirões para confirmação de casos, nem de uma ênfase na busca ativa, mas a investigação dos casos e o diagnóstico de crianças continuam sendo de importância fundamental para acionar a prioridade da prioridade, que continua a existir. A área técnica para a vigilância da SCZ continua sendo um setor específico na SES.

Também há continuidade no serviço prestado pelo Núcleo de Apoio as famílias de crianças com microcefalia (NAFCM), mas há uma ênfase maior em efetivar a regionalização e descentralização da assistência.

Assim, o Estado de Pernambuco seguiu a orientação nacional das 'Diretrizes para organização das ações de atenção e vigilância após o encerramento da Emergência em Saúde Pública de Importância Nacional' (Brasil 2017e), na qual a ênfase está na continuidade das ações realizadas durante o período de emergência.

No final de 2017, a preocupação com a capacidade operacional reduzida de alguns municípios, a sustentabilidade da rede de atenção primária e o acompanhamento em longo prazo, teve como resposta o recebimento de repasse monetário fundo a fundo (Portaria $n^{\circ} 3.502 / 2017$ ), para a continuidade do apoio a Estados e Municípios, principalmente aos serviços de reabilitação e estimulação precoce, no âmbito do processo de regionalização e da ampliação de ações inter setoriais do período pós-emergencial (Brasil 2019b:9).

Em outubro de 2019, havia 34 unidades de saúde prestando pelo menos um serviço estadual de referência, relacionadas a microcefalia, presentes nas 12 gerências regionais do Estado de Pernambuco, reduzindo para no máximo $50 \mathrm{~km}$ a distância de deslocamento para o atendimento dessas crianças (Pernambuco 18/10/2019). O aumento desses serviços de referência, por exemplo, mesmo estando presentes em locais mais próximos da moradia das crianças, ainda se mostram insuficientes, pois as crianças geralmente precisam de mais 
de um tipo de atendimento, para o tratamento de reabilitação ou estimulação precoce.

Também ocorreu, a partir da publicação da Portaria no 3.502/2017, o fortalecimento das ações de cuidado para crianças suspeitas ou confirmadas para a Sindrome Congênita associada não somente ao Zika, mas também à sífilis, toxoplasmose, rubéola, citomegalovírus e herpes simplex (STORCH). Esse fortalecimento foi acompanhado da criação de um comitê gestor estadual para coordenação da execução das atividades e da pactuação de um Plano Estratégico junto à Comissão Intergestores Bipartite (CIB) (Brasil 2019b:9).

A questão financeira de repasses relacionados à infecção pelo Zika, à detecção e tratamento talvez seja o que mais sofreu modificação. $\mathrm{O}$ investimento de organizações internacionais para o financiamento de pesquisas também parece ter diminuído drasticamente. Com a saída do estado de emergência, a obtenção de verbas direcionadas a epidemia diminuíram sensivelmente, encontrando um ambiente de restrições orçamentárias severas para a saúde, devido a aprovação da PEC 95. A vigilância e a assistência organizadas na época da emergência se mantiveram enquanto estruturas e ações, sendo a elas adicionadas agora as síndromes congênitas associadas a outras causas, a CIB e a pactuação do Plano Estratégico.

Talvez isso explique a redução da cobertura aos atendimentos especializados, de puericultura e de estimulação precoce, quando comparados os cumulativos de casos com outros estados, de acordo com o Boletim Epidemiológico Volume 50, No 8 (Brasil 2019b).

Levando em conta os casos notificados em Pernambuco, é possível observar uma queda no percentual de crianças com a SCZ realizando acompanhamento, especialmente a estimulação precoce e o atendimento especializado, quando comparados os casos acumulados no período de 8/11/2015 a 14/01/2017 em relação aos acumulados no período de 08/11/2015 a 29/12/2018 (Quadro 1). 


\begin{tabular}{|c|c|c|c|c|c|c|c|c|}
\hline \multirow[t]{2}{*}{ Fonte } & \multirow[t]{2}{*}{$\begin{array}{c}\text { Período } \\
\text { analisado }\end{array}$} & \multirow[t]{2}{*}{$\begin{array}{c}\text { Total } \\
\text { de casos } \\
\text { confirma- } \\
\text { dos }\end{array}$} & \multicolumn{2}{|c|}{$\begin{array}{l}\text { Atendimen- } \\
\text { to em Pueri- } \\
\text { cultura }\end{array}$} & \multicolumn{2}{|c|}{$\begin{array}{c}\text { Atendi- } \\
\text { mento em } \\
\text { estimulação } \\
\text { precoce }\end{array}$} & \multicolumn{2}{|c|}{$\begin{array}{l}\text { Atendimen- } \\
\text { to especiali- } \\
\text { zado }\end{array}$} \\
\hline & & & $\mathrm{n}$ & $\%$ & n & $\%$ & $\mathrm{n}$ & $\%$ \\
\hline $\begin{array}{l}\text { BE SVS-MS*, } \\
\text { Vol. } 48, N^{\circ} 6 \\
2017\end{array}$ & $\begin{array}{c}8 / 11 / 2015 \\
\text { a } 14 / 01 / 2017\end{array}$ & 392 & 292 & 74,5 & 177 & 45,0 & 391 & 99,7 \\
\hline $\begin{array}{l}\text { BE SVS-MS*, } \\
\text { Vol. } 50, \mathrm{~N}^{\circ} \\
62019\end{array}$ & $\begin{array}{c}08 / 11 / 2015 \text { a } \\
29 / 12 / 2018\end{array}$ & 429 & 294 & 68,5 & 101 & 23,5 & 329 & 76,7 \\
\hline
\end{tabular}

Quadro 1 - Distribuição dos casos confirmados de recém-nascidos e crianças vivas com alterações no crescimento e desenvolvimento relacionados à infecção pelo vírus Zika, segundo atendimento em puericultura, estimulação precoce e atendimento especializado, entre as semanas epidemiológicas 45/2015 e 52/2018, Pernambuco, 2018. Quadro elaborado pelas autoras, de acordo com Boletim Epidemiológico, Secretaria de Vigilância em Saúde do Ministério da Saúde (BE SVS-MS).

Quando escutamos as mães a respeito da realização de exames, tratamento durante o parto e acompanhamento, observamos questões relacionadas à disponibilidade dos serviços e a qualidade do atendimento que os esforços e o trabalho intensivo da atenção em saúde não parecem alcançar.

\section{Exames, atendimento e acompanhamento das gestantes e mães}

Os resultados dos exames e o tratamento dado a elas pelos profissionais de saúde compõem fontes de reclamação das mães. Nesse trabalho, privilegiamos os exames porque fazem parte da espinha dorsal das ações de detecção e controle da epidemia, espelhando vários esforços realizados durante o estado de emergência, tais como a busca ativa, a notificação, a confirmação e a 'prioridade da prioridade' no atendimento. Todas essas mães foram entrevistadas entre 2017 e 2018, reportando fatos ocorridos na época da emergência e do pós-emergência. 
Como evidenciamos em outro trabalho (Quadros, Scott \& Faya 2020), os exames de detecção e confirmação diagnóstica incluem ultrassonografia obstétrica; ultrassonografia transfontanelar e tomografia do crânio sem contraste. Exames de sangue e urina, ou do cordão umbilical, placenta e líquor, eram coletados no momento do parto quando havia alguma indicação de que o bebê era portador da microcefalia no prénatal.

Apesar da importância desses procedimentos serem reconhecidos como importantes por mães, profissionais de saúde e pesquisadores, contendo técnicas e procedimentos protocolares e envolvendo profissionais comprometidos, havia falhas e precariedade na estrutura do atendimento. Alguns dos exames, feitos por grupos de pesquisa ou em laboratórios da rede tinham resultados retidos ou havia demora na confirmação de alguns casos, o que acabava por impedir o acesso das crianças aos benefícios do estado de emergência (Matos, Quadros \& Silva 2019; Silva, Matos \& Quadros 2017).

A precariedade do sistema de saúde brasileiro impulsionou as cuidadoras e grupos solidários a estruturarem outros espaços de cuidado associados ao mercado, ONGs, associações sem fins lucrativos, instituições filantrópicas e trabalhos voluntários (Scott et al 2017; Scott et al 2018).

As associações de mães são espaços privilegiados nos quais as mães/cuidadoras organizam a experiência de ter uma criança com SCZ por meio de um processo de sociabilidade que valoriza o reconhecimento a partir da parentalidade, como 'mãe especial', 'mãe rara', 'mãe de anjo' e suas experiências como 'sacrifício', 'luta', 'força', 'benção', num processo de positivação da experiência, na qual a maternidade e o cuidado estão profundamente interligados (Scott et al 2017).

Em Recife, duas associações congregam uma variada gama de esferas do cuidado, a União de Mãe de Anjos (UMA) e a Aliança de Mães e Famílias Raras (AMAR), nas quais a equipe de pesquisa realizou etnografias. Como observamos em outro artigo (Scott et al 2017), 
algumas reflexões sobre cuidado e peso social para as cuidadoras estão relacionadas ao papel político dessas associações na mediação com o Estado, fortalecendo as mães para a luta por políticas públicas, já com alguns resultados como a campanha que culminou com a distribuição do remédio Kepra (anticonvulsivante) pelo SUS e o aumento no número de médicos especializados em neurologia pediátrica na Secretaria Estadual de Saúde.

A organização de muitas mães em associações auxilia no acompanhamento do tratamento e na luta pelos direitos das crianças, no enfrentamento dos preconceitos sofridos pelas crianças, dos problemas com resultados de exames não fornecidos, na demora da confirmação das notificações, dos casos de crianças que ficavam muito tempo em investigação. Uma mãe cujo parto aconteceu numa maternidade da rede particular evidenciou sua tristeza em relação ao tratamento dado ao seu filho no berçário e, posteriormente, sua decepção com a falta de entrega do resultado de um exame:

Marília: Quiseram logo esconder ele do berçário, botaram um lençol [...]. Pra não mostrar, creio eu que eles não queriam chocar os pais que estavam ali esperando as outras crianças esteticamente perfeitas, né?[...]. E foi aquele processo, né? Fazer os exames. Ai a gente pegou, fez todos os exames, aí com dois dias, ele fez o LCR [exame do liquor] com um laboratório que trabalha para o SUS também e esse exame extraviaram.

Luciana Lira: Foi mesmo? Você não teve acesso?

Marília: Não a esse exame, com menos de um mês, João foi submetido a outro, agora na rede pública, que era para ter segurança, pergunte-me se eu tenho o resultado desse exame até hoje, não tenho, por quê? Porque todos os outros exames que ele fez deu tudo negativo, Toxoplasmose, num sei o quê, todos deram negativo. E o Estado sabe que ele é do Zika Vírus, tá lá, tem até um ofício que mandaram para a Secretaria de Paulista, uma pessoa me deu, os que foram confirmados [...]. Mas o laudo da Secretaria de Saúde nós não temos. ${ }^{10}$

Uma outra mãe destaca esse problema da entrega parcial de exames, uma realidade que vimos ocorrer algumas vezes durante o trabalho de campo: 
Alice: Porque mainha [avó do seu filho] entrou na sala e fez a tomografia, e para retirar o líquido eu tive que ficar com ele, né? Aí retirou o líquido que até hoje eu não tive esse resultado, mas na imagem viu que ele tinha calcificação e viu que ele tinha o zika mesmo, né? Pronto, aí começou a batalha, hoje eu consigo falar assim sem choro e forte porque assim, são três anos, né? ${ }^{11}$

Tensão e descontentamento aumentaram com a demora na entrega de resultados de exames e de confirmação de casos, levando algumas mães a questionarem o papel dos seus filhos e filhas na epidemia, elas sentiam que seus filhos eram tratados como cobaias, objetos de manipulação e pesquisa (Matos, Silva \& Quadros 2017; Matos \& Quadros 2018). De acordo com Silvana Matos \& Marion T. de Quadros (2018), elas reclamavam que seus filhos não eram apenas uma gota de sangue, urina ou saliva. Esse sentimento decorria da falta de retorno de resultados dos exames e achados clínicos nos seus filhos, informações que, às vezes, chegavam a elas após a publicação de artigos científicos ou das reportagens em jornais e revistas (Matos, Silva \& Quadros 2017).

Uma rotina extressante é a expressão do que ocorre com as mães durante a realização de exames e diagnósticos, até a decisão de deixar o emprego ou largar os estudos, e a mobilização intensiva para os locais de tratamento e reabilitação. São viajens constantes para clínicas, hospitais, fundações, centros de reabilitação, nos quais os tratamentos de estimulação precoce geralmente incluem fisioterapia, fonoaudologia e terapia ocupacional, que muitas vezes são realizados em locais diferentes. É uma mudança radical na vida dessas mães, acompanhada de pouca rede de apoio familiar e abandono por parte do pai da criança, em muitos casos. Uma mãe nos contou sua rotina diária:

Severina: Então, sábado, domingo e segunda a gente tá de folga, aí terça a gente vai para a fisio, a gente sai às cinco da manhã, aí faz as terapias que é o auditivo, visual, fonoaudióloga, terapeuta ocupacional e fisioterapia.[...] aí na terça feira a gente tem essa rotina, aí umas dez e meia onze horas a gente tá vindo embora, aí 
pronto, a gente chega em casa, cuido de Joana, almoçar e dormir a tarde inteira, porque o que enfada a gente não é as terapias, mas as viagens e a espera, aí nas quartas feiras de vez em quando tem uns atendimentos marcados mensalmente, infectologista, neurologista e gastro.

Shirley Souza: Aonde?

Severina: No IFP e no [Hospital] Oswaldo Cruz. Na quinta feira a gente faz atendimento na Nassau [Universidade Maurício de Nassau], faz acompanhamento com uma fisioterapeuta, tá na fila de espera pra fazer fisioterapia, já vai fazer dois anos e a gente não conseguiu ainda, na quinta a gente só faz isso, e na sexta feira a gente vem para PAN à tarde, a gente faz a fono, fisio e TO. ${ }^{12}$

Em decorrência de todos esses acontecimentos, a maior parte das mães alarga o sentido de cuidadora. É possível ver a exacerbação do trabalho de cuidado e da maternidade enquanto dedicação e priorização da criança em detrimento de outros projetos ou atividades, além de enfrentamento ao preconceito em relação aos seus filhos. A maternidade é vista como uma missão para prover a qualidade de vida da criança (Lira, Scott \&Meira 2018; Quadros, Scott \& Faya 2020).

Além disso, a falta de informação, a dificuldade de acesso a exames e as longas distâncias e jornadas para o tratamento das crianças são realidades presentes durante e após o estado de emergência.

\section{Considerações finais}

O maior aporte de recursos e a evidência midiática que estiveram presentes no estado de emergência e agora já não são mais uma realidade, parece ter influenciado pouco certas características da interação entre o sistema de cuidado do atendimento público à saúde e as práticas de cuidado materno. Rotina estressante, falta de tempo para outras atividades, esforços variados para identificar e diagnosticar a SCZ, problemas com transporte, muito tempo para transporte e realização de consultas, terapias e exames, cuidados com alimentação, higiene, convulsões e outros problemas neurológicos, musculares, auditivos e oftalmológicos, luta para ter acesso aos medicamentos e às consultas, 
dedicação em tempo integral às crianças não deixaram de fazer parte da vida dessas mães.

Identificamos o momento de descoberta e diagnóstico como muito sofrido e estressante, bem como as consultas e o tratamento. Em todos eles, há uma dedicação integral da mãe, que é a pessoa a quem os serviços de atendimento se dirigem preferencialmente. É contando com a 'responsabilidade' das mães que os problemas de acesso acabam por resultar nas dificuldades e sacrifícios das mães cuidadoras. Foi possivel perceber por parte da SES a preocupação com as crianças e suas famílias, especialmente as mães, na continuidade observada na sua estrutura organizacional, na ampliação da estrutura de atendimento após o período emergencial, entre outras. Porém, isso não modificou muito a realidade dessas mulheres. São elas que, mesmo contando com a estrutura institucional que as colocam como prioridade da prioridade, vão arcar com rotinas pesadas de deslocamentos para atendimento dos seus filhos potencializando o cuidado materno.

Por outro lado, é importante frisar que muitas mães parecem ter percebido isso e a atuação das associações UMA e AMAR refletem uma interlocução com o Estado e o sistema de saúde, que evidenciam o empoderamento das mães cuidadoras em relação à luta por melhorias e acesso às necessidades de seus filhos.

$\mathrm{Na}$ assistência às crianças com $\mathrm{SCZ}$, as respostas são tensionadas e parciais. A família perderá renda de um dos adultos, geralmente a mãe, que deixará seu emprego para cuidar da criança que, por sua vez apresentará problemas de disfagia, criando a necessidade do uso de suplementos alimentares extremamente onerosos, não distribuídos pelo Estado. Além disso, são necessários outros remédios e materiais (oxímetros, sondas, talas, parapodium ortostático, cadeiras, fraldas, materiais de higiene pessoal) para a rotina do cuidado dessas crianças, onerando o orçamento doméstico das famílias, vulnerabilizando-as ainda mais em termos econômicos e sociais (Scott et al 2018). Nesse contexto, a relação entre Estado e cidadã se transforma numa disputa desigual, por vezes judicializada, para a obtenção de direitos relaciona- 
dos ao cuidado da criança e à sobrevivência da família (Matos, Quadros \& Silva 2019).

No tempo da epidemia houve maior articulação entre várias instâncias da atenção a saúde para atender as demandas das crianças com SCZ. Na medida em que a epidemia acabou, as mães cuidadoras foram ganhando maior protagonismo no que se refere à luta pela garantia dos direitos dos seus filhos/as, as associações ganharam mais força enquanto coletivo atuante em espaços políticos como, por exemplo, no processo que envolveu a aprovação da Lei no 13.985 (07/04/2020), que concede pensão vitalícia a crianças com a SCZ. A emergência teve um final para o Estado, mas para as mães tudo ainda é emergencial, afinal a condição de suas crianças permanecerá no cuidado cotidiano e na relação com os serviços.

Assim, o trabalho de cuidado vai se moldando, pelo caráter emergencial, ao tempo da epidemia e ao tempo posterior à finalização do estado de emergência. Por meio desse trabalho as mulheres cuidadoras muitas vezes se fortalecem ou se politizam tanto na esfera pública (assistência social e de saúde) quanto na esfera privada (cuidados cotidianos). Ao lidar com o peso social do Zika, em uma sociedade na qual a posição e os direitos das mulheres são permeados por muitas discriminações de gênero, raça e classe, a experiência do cuidado com uma síndrome desconhecida empoderou algumas mulheres no campo político, um dos resultados positivos para a mudança de vida e a sobrecarga de trabalho e responsabilidades que recaíram sobre os seus ombros.

\section{Notas:}

1 Uma versão preliminar desse artigo foi apresentada como comunicação no VII Congresso da Associação Portuguesa de Antropologia que decorreu de 4 a 7 de junho de 2019 em Lisboa (Portugal), na Faculdade de Ciências Sociais e Humanas da universidade Nova de Lisboa.

2 A pesquisa 'Etnografando Cuidados e Pensando Políticas de Saúde e Gestão de Serviços para Mulheres e Seus Filhos com Distúrbios Neurológicos Relacionados com Zika em Pernambuco, Brasil' sob a coordenação de Russell Parry Scott 
do FAGES (Núcleo de Família, Gênero, Sexualidade e Saúde) da Universidade Federal de Pernambuco, tem o apoio de CAPES (8888.130742/2016-01), CNPq (440411/2016-5), Decit/SCTIE/MS, e, sob o título 'Action Ethnography on Care, Disability and Health Policy and Administration of Public Service for Women and Caretakers of Zika vírus affected Children in Pernambuco, Brazil', tem o apoio de FACEPE/ Newton Fund (APQ 0553-7.03/16). Este artigo também fez parte das atividades de estagio pós-doutoral da autora Marion Teodósio de Quadros, por meio da bolsa PDE CNPq, processo n. 204337/2018-6.

3 Agradecemos especialmente a Parry Scott, coordenador da pesquisa, pela leitura cuidadosa e sugestões dadas a este artigo.

4 As secretarias municipais de saúde formam a base de atendimento dos serviços oferecidos. Entretanto, não foi possível a pesquisa 'Etnografando Cuidados' a permissão para pesquisar os múltiplos espaços de atuação dos serviços municipais, devido às restrições elucidadas pelo parecer do comitê de ética das secretarias municipais consultadas.

5 Além das entrevistas com alguns gestores, foram fontes as notícias postadas no portal.saude.pe.gov.br pela Secretaria Executiva de Coordenação Geral e pela Secretaria Executiva de Vigilância em Saúde. Também utilizamos informações contidas em apresentação de slides da Secretaria Estadual de Saúde de Pernambuco para a rede de atenção primária em setembro de 2017. Disponível em https://apsredes. org/wp-content/uploads/2017/09/Apres-SES-PERNAMBUCO.pdf.

6 Entrevista realizada por Silvana Matos com uma gestora em 13/06/18, para a pesquisa Etnografando Cuidados.

7 Informações contidas em apresentação de slides da Secretaria Estadual de Saúde de Pernambuco para a rede de atenção primária em setembro de 2017, disponível em https://apsredes.org/wp-content/uploads/2017/09/Apres-SES-PERNAMBUCO.pdf.

8 Informações contidas em apresentação de slides da Secretaria Estadual de Saúde de Pernambuco para a rede de atenção primária em setembro de 2017, disponível em https://apsredes.org/wp-content/uploads/2017/09/Apres-SES-PERNAMBUCO.pdf. Esta mesma informação consta em tabelas que recebemos, durante o processo de pesquisa, da equipe da SES com a qual estabelecemos contato.

9 Entrevista realizada por Silvana Matos e Isabele Batchold, no dia 19/06/18 para pesquisa 'Etnografando Cuidados'.

10 Entrevista realizada por Silvana Matos e Luciana Lira, em 2017, para pesquisa 'Etnografando Cuidados'. Os nomes das mães e crianças contidos nos trechos de entrevistas deste artigo são fictícios para preservar o anonimato.

11 Entrevista realizada por Silvana Matos, Luciana Lira e Fernanda Meira, em 2017, para pesquisa 'Etnografando Cuidados'.

12 Entrevista realizada por Shirley Souza, em 2017, para a pesquisa 'Etnografando Cuidados'.

\section{Referências:}

AYRES, José R. 2009. Cuidado: trabalho e interação nas práticas de saúde. Rio: CEPESC - IMS/UERJ - ABRASCO. 
BRASIL, Ministério da Saúde. 2019a. "Monitoramento integrado de alteraç̃es no crescimento e desenvolvimento relacionadas à infecção pelo vírus Zika e outras etiologias infecciosas, até a Semana Epidemiológica 52 de 2018”. Boletim Epidemiológico, 50(8):1-8. (https://portalarquivos2.saude.gov.br/ images/pdf/2019/marco/22/2019-001.pdf; acesso em 29/05/2019).

. 2019b. "Síndrome congênita associada à infecção pelo vírus Zika: situação epidemiológica, ações desenvolvidas e desafios, 2015 a 2019”. Boletim Epidemiológico, 50(n.esp.):1-31. (www.saude.gov.br/boletins-epidemiologicos; acesso em 03/04/2020).

. 2017a. "Monitoramento integrado de alterações no crescimento e desenvolvimento relacionadas à infecção pelo vírus Zika e outras etiologias infecciosas, da Semana Epidemiológica 45/2015 até a Semana Epidemiológica 02/2017”. Boletim Epidemiológico, 48(6):1-18. (https:// portalarquivos2.saude.gov.br/images/pdf/2017/fevereiro/27/2017_003.pdf; acesso em: 22/05/2019).

. 2017b. Virus Zika no Brasil: a resposta do SUS. Brasília: Ministério da Saúde.

2017c. Ministério da Saúde declara fim da Emergência Nacional para

Zika e microcefalia. (www.saude.gov.br/noticias/svs/28348-ministerio-dasaude-declara-fim-da-emergencia-nacional-para-zika-e-microcefalia; acesso em 05/04/2020).

. 2017e. Nota Informativa Conjunta N.` 05: Diretrizes para organização das ações de atenção e vigilância após o encerramento da Emergência em Saúde Pública de Importância Nacional (ESPIN) por alteração do padrão de ocorrência de microcefalias no Brasil e desativação do Centro de Operações de Emergências em Saúde Pública (COES). (https://12ad4c92-89c7-4218-9e11-0ee136fa4b92.filesusr.com/ugd/3293a _ c4aecbdbf5554cd281e9fd8b28d381a1.pdf, acesso em 03/04/2020).

2016. "Monitoramento dos casos de microcefalia no Brasil até a Semana Epidemiológica 51/2015”. Boletim Epidemiológico, 47(1):1-4. (https:// portalarquivos2.saude.gov.br/images/pdf/2016/janeiro/11/2015-053-parasubstituir-na-p-gina.pdf; acesso em 04/06/2019).

BRITO, Carlos. 2017. "Investigação de um surto - aprendizado para a comunidade assistencial e a saúde pública". In BRASIL. Ministério da Saúde ed.): Virus Zika no Brasil: a resposta do SUS, pp. 27-40. Brasília: Ministério da Saúde.

BROOKS, B. 2016. "Infrastructure inequality is catalyst for Brazil's Zika epidemic". Reuters Life, 15 março. (www.reuters.com/article/us-health-zikainequality-insight; aceso em 30/04/2020).

BUENO, Flávia. 2017. "Vigilância e resposta em saúde no plano regional: um estudo preliminar do caso da febre do Zika vírus". Ciência Ë Saúde Coletiva, 22(7):2305-2314.

CAMPOS, R., QUADROS, M. \& SANTOS, D. 2010. O que é do afeto é de direito? Mudança social, parentesco e sistema jurídico brasileiro. Trabalho apresentado na 27a Reunião Brasileira de Antropologia, Belém- PA.. 
CORNWALL, A. \& SHANKLAND, A. 2008. "Engaging Citizens: Lessons from Building Brazil's National Health System”. Social Science $\mathbb{E}$ Medicine, 66(10):2173-84.

DINIZ, Deborah. 2007. O que é deficiência?. São Paulo: Brasiliense. . 2016. 'The Zika Virus and Brazilian Women's Right to Choose'. The New York Times, 8 February.

LANGDON, E., FOLLÉR, M. \& MALUF, S. 2012. "Um balanço da antropologia da saúde no Brasil e seus diálogos com as antropologias mundiais". Anuário Antropológico, 1:51-89.

FURTADO J. et al. 2018. "Planejamento e Avaliação em Saúde: entre antagonismo e colaboração". Cad. Saúde Pública, 34(7):e00087917. (www.scielo.br/pdf/csp/ v34n7/1678-4464-csp-34-07-e00089717.pdf; acesso em 15/04/2020).

GARCIA, Leila. 2018. Epidemia do Virus Zika e Microcefalia no Brasil: emergência, evolução e enfrentamento. Texto para discussão. Brasília/Rio de Janeiro: Instituto de Pesquisa Econômica Aplicada.

GUIMARÃES, N., HIRATA, H. \& SUGITA, K. 2011. "Cuidado e cuidadoras: o trabalho de care no Brasil, França e Japão". Sociologia e Antropologia, 1(1):151-180.

GUSSI, A. \& OLIVEIRA, B. 2016. "Políticas públicas e outra perspectiva de avaliação: uma abordagem antropológica”. Desenvolvimento em Debate (INCT/PPED), 4:83-101.

HEYMANN, D. et al. 2016. "Zika virus and microcephaly: why is this situation a PHEIC?" The Lancet, 387(10020):719-721.

HIRATA, H. \& GUIMARÃES, N. (eds). 2012. Cuidado e Cuidadoras: as várias faces do trabalho do care. São Paulo: Editora Atlas.

HIRATA, H. \& DEBERT, G. 2016. "Apresentação”. Cadrnos Pagu, (46):7-15.

HIRATA, Helena. 2016. "O trabalho do cuidado: comparando Brasil, França e Japão”, SUR 24, 13(24):53-64.

LANGDON, Esther. 2014. "Os diálogos da antropologia com a saúde: contribuições para as políticas públicas". Ciência E⿱ Saúde Coletiva, 19(4):1019-1029.

LEACH, Melissa. 2015. "The Ebola crisis and post-2015 development". Journal of International Development, 27:816-834.

LIMA, Antónia. 2016. "Care as a factor for sustainability in situations of crisis: Portugal between the Welfare State and interpersonal relationships”. Cadernos Pagu, (46):79-105.

LIRA, L., SCOTT, P. \& MEIRA, F. 2017. "Cuidando de Corpos: trocas, gênero, assimetrias e alinhamento na experiência etnográfica com mães e crianças com síndrome congênita do Zika”. Revista Anthropológicas, 28(2):206-237.

MATOS, S. \& QUADROS, M. 2018. A construção da deficiência em Síndrome Congênita do Zika virus: o discurso das famílias afetadas e do Estado. Trabalho apresentado no 18th IAUES World Congress. Florianópolis-SC.

MATOS, S., QUADROS, M. \& SILVA, A. C. 2019. "A negociação do acesso ao Benefício de Prestação Continuada por crianças com Síndrome Congênita do Zika Vírus em Pernambuco”. Anuário Antropológico, 44(2):229-260. 
MATOS, S., SILVA, A. C. \& QUADROS, M. 2018. How can anthropology work? Dialogue between research and care in the case of the Congenital Syndrome of the Zika Virus in Pernambuco/ Brazil. Trabalho apresentado no $18^{\circ}$ Congresso Mundial de Antropologia, Florianópolis-SC.

MINAYO, Maria C. 2000. O desafio doconhecimento: Pesquisa qualitativa em saúde. São Paulo/ Rio de Janeiro: Hucitec/ Abrasco.

PERNAMBUCO, Secretaria de Desenvolvimento Social, Criança e Juventude e Secretaria Executiva de Assistência Social. 2019. "Síndrome Congênita de Zika Vírus em Pernambuco: Perfil das Famílias e Mães identificadas no Cadastro Único para Programas Sociais”. Boletim Informativo, n.1, Recife, 12 março. (www.sigas.pe.gov.br/files/04092019085542-boletim.informativo. no.01.2019.sindrome.congenita.de.zika.virus.pdf; acesso em 22/05/2019).

PERNAMBUCO, Secretaria Estadual de Saúde. 2019. Zika: SES sedia roda de conversa sobre pesquisa da UFPE. (http://portal.saude.pe.gov.br/noticias/ secretaria/zika-ses-sedia-roda-de-conversa-sobre-pesquisa-da-ufpe; acesso em 03/04/2020).

2018. SCZ/microcefalia: Profissionais de Saúde são capacitados em Caruaru. (http:// portal.saude.pe.gov.br/noticias/secretaria-executiva-decoordenacao-geral/sczmicrocefalia-profissionais-de-saude-sao via @saudePE; acesso em 03/04/2020).

2016. Governo lança plano de combate às arboviroses. (http://portal. saude.pe.gov.br/noticias/secretaria-executiva-de-vigilancia-em-saude/governolanca-plano-de-combate-arboviroses via @saudePE; aacesso em 03/04/2020).

QUADROS, M., SCOTT, P. \& FAYA ROBLES, A. 2020. “'Crianças Especiais', 'Bebês Micro', 'Bebês anjos': objetivações e subjetivações de corpos infantis em um contexto de emergência em Saúde". In ALLẺBRANDT, D. et al. (eds): Desigualdades e Políticas da Ciência. Porto Alegre: Editora Casa Verde (no prelo).

SCAVONE, Lucila. 2001."Maternidade: transformações na família e nas relações de gênero". Interface: Comunicação, Saúde, Educação, 8(5):47-60.

2004. Dar a vida e cuidar da vida: feminismo e ciências sociais. São Paulo: Editora Unesp.

SCOTT, R. et al. 2018. "Itinerários terapêuticos, cuidados e atendimento na construção de ideias sobre maternidade e infância no contexto da Zika." Interface (Botucatu), 22(66):673-684.

SCOTT, R. et al. 2017. "Epidemia de Zika e as Articulações das Mães num Campo Tensionado entre Feminismo, Deficiência e Cuidados." Cadernos Gênero e Diversidade, 3(2):73-92.

SHANKLAND, A. \& CORNWALL, A. 2017. "Realizing Health Rights in Brazil: The Micropolitics of Sustaining Health System Reform". In BEBBINGTON, A. \& McCourt, W. (eds.): Development Success: Statecraft in the South, pp. 163. 188. Basingstoke: Palgrave Macmillan.

SILVA, A. C., MATOS, S. \& QUADROS, M. 2017. "Economia Política do Zika: Realçando relações entre Estado e cidadão." Revista Anthropológicas, 28(1):223-246. 
SPIESS, Marcos. 2016. "Relações entre antropologia e políticas públicas no Brasil: uma análise da institucionalização do campo de pesquisa". Perspectivas em Políticas Públicas, IX(17):169-191.

SULLIVAN, Z. 2016. "Living with Zika in Brazil: Microcephaly epidemic highlights the inequality experienced by low income communities and women". Al Jazeera, 13 April. (www.aljazeera.com/indepth/ features/2016/03/living-zika-brazil-160329192855371.html; acesso em 02/04/2020).

TRONTO, Joan. 2013. Caring Democracy. Markets, Equality, and Justice. New York: NYU Press.

. 1997. "Mulheres e cuidados: o que as feministas podem aprender sobre a moralidade a partir disso?" In JAGGAR, A. \& BORDO, S. (eds.): Género, corpo, conhecimento, pp.186-203. Rio de Janeiro: Record/ Rosa dos Tempos.

UNNITHAN, M., MACGREGOR, H. \& CASSELL, J. 2016. "What does Zika mean for sexual and reproductive health and rights?". IDS Blog, 8 February. (www.ids.ac.uk/opinions/what-does-zika-mean-for-sexual-and-reproductivehealth-and-rights/; acesso em 02/04/2020)

WILKINSON, A. \& M. LEACH. 2014. "Ebola: myths, realities and structural violence". African Affairs, 114 (454):136-14.

\begin{abstract}
The birth of children with Congenital Zika Virus Syndrome (SCZ), especially in the Northeast region, caused Pernambuco, Brazil and WHO to declare a public health emergency. This article addresses some of the continuities and discontinuities perceived in relation to assistance during the state of emergency in public health and after its completion, appreciating how the State Department of Health (SES) responded to the end of the epidemic and the social burden of the disease for mothers, in the process of discovering and treating children's SCZ, comparing testimonies and observations of professionals and mothers of children with SCZ, in Pernambuco, the epicenter of the epidemic. It is part of the anthropological research "Ethnographing care", which started in 2016. The first and second items reflect on institutional actions, mainly from SES. The third item emphasizes how the mothers of children with SCZ perceive what is coming to them through public assistance services.
\end{abstract}

Keywords: Zika virus, Public health, Care, Gender, Maternity.

Recebido em Dezembro 2019.

Aprovado em Janeiro 2020. 